\title{
A Processual Approach for the Quadruple Helix Model: the Case of a Regional Project in Uppsala
}

\author{
Jessica García-Terán ${ }^{1}$ • Annika Skoglund ${ }^{1}$
}

Received: 20 January 2017 / Accepted: 23 January 2018 /Published online: 2 March 2018

(C) The Author(s) 2018. This article is an open access publication

\begin{abstract}
This study investigates how the quadruple helix (QH) innovation model functions in a regional renewable energy initiative in Uppsala, Sweden. The focus is on the collaboration between regional office representatives, researchers, consultants and civil society, and their involvement in the attempt to implement and commercialize an innovation within renewable energy for the renovation of an old bridge. The empirical material gathered for this study was based on interviews, conversations, and participant observation during workshops and meetings with different stakeholders. By applying a processual approach, this article illustrates how the QH configuration (universityindustry-government and civil society) emerges and evolves, unfortunately into a failed collaboration and thus a closing down of a commercialization attempt. By analyzing interactions and events of the process, we discuss the coordination problems between the actors to better understand how the dynamics affect local governments' attempts to spur a more innovative climate in the region. In our conclusion, we discuss how the processual approach, when applied, can offer a better understanding of the uncertain development of QH projects in knowledge-based societies and economies.
\end{abstract}

Keywords Interactions - Commercialization - Entrepreneurship · Process studies · Quadruple helix

\section{Introduction}

The triple helix (TH) concept emerged from studies of how governments partner with universities and industries to accomplish a more innovative climate (Etzkowitz 2008). Carayannis and Campbell $(2009,2011)$ defined the quadruple helix $(\mathrm{QH})$ as an extension of the TH model to account for the role of civil society and how people

Jessica García-Terán

jessica.garcia@angstrom.uu.se

1 Industrial Engineering and Management, Uppsala University, Box 534, 75121 Uppsala, Sweden 
are invited to participate in the creation of knowledge and innovation. Theoretically, the helix model refers to structures and processes where the diversity of agents are arranged into "fluid and heterogeneous innovation networks" (Carayannis and Campbell 2011, p. 342) in which innovations are conceived to be stimulated by a co-creation process among the actors (Füzi 2013) and where a "fluid movement of knowledge" takes place (MacGregor et al. 2010, p. 186). Nonetheless, few helix studies address the interactions and events involved in $\mathrm{QH}$ configurations (university-industry-government and civil society) as a process (see Lindberg et al. 2014; Björk 2014). The purpose of this paper is to better understand $\mathrm{QH}$ configurations when it comes to their processual nature, i.e., how they emerge and evolve.

To address this research curiosity, we turn to a project initiated by the regional office in Uppsala, Sweden. The regional office contacted the local university to integrate an innovation within renewable energy technology in the renovation of an old bridge. The purpose of working together with the university was, in addition to the renovation, to support a spinoff company and facilitate a commercialization of renewable technology in the region. Empirical material was collected over 2 years by following the planning of the renovation project. During this time, the actors under study were local authorities working for the regional office at Uppsala municipality, a group of researchers at Uppsala University, and a spinoff company holding the patent for a marine current power turbine. External consultants and members of the civil society were also included in the collection of empirical material as they later became involved with the project.

The analytical interest in a processual perspective aligns with an interest in how collaborations develop over time, where specifically the interactions between actors are suggested to be complex in commercialization of energy-related innovations (Dougherty and Dunne 2011). The transformation of societies into more sustainable ones is additionally recognized as complex since it demands multifaceted knowledge production and dissemination (Grundel and Dahlström 2016), where a smooth step-bystep inclusion of the general public, the fourth helix, is of utmost importance (Carayannis and Campbell 2011). Hence, instead of looking at the QH as a model for systematic stimulation of innovations and commercialization, this article focuses on how a specific collaboration unfolds and how helices are shaped processually via micro-processes of change (e.g., see Tsoukas and Chia 2002). This contributes to both an empirical in-depth description of a commercialization process and a theoretical advancement of the processual nature of the helix model. To be able to craft our contribution, we turn to process studies of entrepreneurship (Steyaert 1997, 2007; McMullen and Dimov 2013; Hjorth et al. 2015). We relate to entrepreneurship since the entrepreneurial university inspired the helix concept in the first place (Etzkowitz 1983) and since the helix model focuses on how to foster an innovative environment for new firms, organizations, initiatives, and strategic alliances (Etzkowitz and Leydesdorff 2000), which are linked to the entrepreneurial process (Lindberg et al. 2014).

The article starts with an introduction to the $\mathrm{QH}$ innovation model, followed by an application of the processual approach. Then we describe the method by which the material has been collected, as well as the analytical framework used to understand the micro-processes of change. Thereafter follows the analysis of interactions and events, presented as a narrative of how the helices unfold over time. Next, we discuss our 
findings and explore the theoretical possibilities and pitfalls for understanding the helix model processually. Finally, we pin down the practical implications for local authorities that are interested in directing similar entrepreneurial processes in dialog with the university and civil society.

\section{The Quadruple Helix}

The collaborations formed between state, business, and academia, known as the TH innovation system, have been studied for the past few decades (Leydesdorff and Etzkowitz 1996; Leydesdorff 2003; Leydesdorff and Park 2014), at the regional level (Schoonmaker and Carayannis 2013) and at the national level (Leydesdorff 2012). A fourth helix has also been added to include the role of "a media-based and culturebased public" and civil society (Carayannis and Campbell 2009, p. 206; 2011, p. 338) in innovation processes. The media, with general cultural expressions and values (ibid 2011), are seen as part of how public reality is constructed in national innovation systems (ibid, 2009). For example, through media, startup competitions can improve a firm's reputation and facilitate legitimacy (Parente et al. 2015). Thus, media attention can influence the effects of startup competitions on supporting technology transfer processes of academic spinoffs (ibid). Hence, the fourth helix often refers to how users and citizens are invited via media, information campaigns and other channels (Arnkil et al. 2010; Füzi 2013). As governments formulate policies and support the development of science-based technologies, the fourth helix is suggested to bring competitive advantage to the industry if citizens get involved in the innovation process. The fourth helix is also investigated as "innovation intermediaries" that are based in universities to support small and medium enterprises (Betz et al. 2016). Among other examples are entrepreneurs who are driving regional development (Carayannis and Rakhmatullin 2014), in rural and less-favored regions, where the community often plays a dominant entrepreneurial role to enhance innovation (Kolehmainen et al. 2016), and in the forestry-based bioeconomy in Sweden, where the aim is to add the perspectives and expertise from civil society and citizens to further develop the bioeconomy in the region (Grundel and Dahlström 2016). However, the authors (ibid) highlight that there is no clear direction on how the civil society is supposed to be part of the transformation process, in this particular case, and that so far, there has been no involvement of the fourth helix. As argued, "the links between civil society and the municipalities were not based on innovation or innovation policy" (ibid, n.p.). Rather, the relationships between the municipality and civil society concern other important aspects such as the development of strategic plans in the region, or matters of how to create a good life for its citizens. Lindberg et al. (2012, p. 37) highlight that it is only by interactions and networks extended to the civil society that "creative knowledge environments" can prosper. Intermediate organizations, such as NGOs, are consequently targeted for a more effective inclusion of civil society actors in innovation programs and projects (Lindberg et al. 2014). Better communication between different actors has in addition been recognized as needed, particularly for the engagement of the civil society, as they commonly feel left out of decision-making processes (Grundel and Dahlström 2016). Kolehmainen et al. (2016) suggest strategic thinking and actions, mutual interest, and commitment as of great importance for $\mathrm{QH}$ collaborations. Features of social organization, such as trust, norms, and networks, can also facilitate 
collaborative actions (Aranguren and Larrea 2011). Hence, a common language and a shared understanding on the possible solution and potential alternatives can positively impact the dynamics of organizations (Di Nauta et al. 2015). The main hurdles for collaborations are the setting up of an innovation-friendly ecosystem (Casaramona et al. 2015). This has been attempted through democratic processes that gives civil society "the possibility of participating realistically in political processes" (Campbell et al. 2015, p. 474). That is, not only in order to "secure commitment and reduce resistance", as frequently practiced by consultants (Strannegård and Styhre 2013, p. 64). This ideal of deliberative democracy is also recognized as necessary for a $\mathrm{QH}$ innovation system. Similarly to Casaramona et al. (2015), Nordberg (2015, p. 344) suggests to aim for the construction of an innovation-friendly culture when implementing the QH concept via "the actual and purposive inclusion of society in the innovation process."

In developing the $\mathrm{QH}$ model, the fourth helix has been defined in various ways. However, a common denominator to these definitions is that an added helix "adds knowledge of human life to the innovation process, alongside scientific and technological knowledge" (ibid, p. 343, italics in original). The helix model has also been advanced to include a fifth helix to bring in natural environments in order to promote sustainable development. It accounts for "nature" as a central component for innovation (Carayannis et al. 2012). This fifth helix does, however, differ from the other helices in the sense that it grants agency to non-human organics. In comparison to the other four helices that consist of human actors, the fifth helix constitutes nature or the environment as an actor. On the other hand, the fourth helix can also be inclusive of environmental movements and green NGOs that take it upon themselves to speak on behalf of nature.

Other QH studies propose to understand the model in a circular perspective (Afonso et al. 2012), where government provides public goods by spending on education, health, infrastructure, technology, etc., to increase the economic growth rate of $\mathrm{QH}$ economies. Colapinto and Porlezza (2012), for instance, use systems theory to advance the $\mathrm{QH}$ model and better understand the macro-level in different functional systems, i.e., the relationships between politics, economy, media and science. They (ibid) present the "networked economy" as the main force transforming a region. Regional innovation systems are also studied by way of the exploration into the distribution of innovation resources and the interactions among actors within and between regions, particularly in Sweden (Danell and Persson 2003). Jensen and Tragardh (2004) exemplify this in their investigation of the TH concept in Sweden, with a focus on weak regions. The authors show how, in weak regions, economic growth can be an easy thing to plan through TH collaborations, but that these plans are difficult to manage and implement (ibid). More recently, Prónay and Buzás (2015) have contributed to the debate by their exploration of the link between marketing and innovation, suggesting a new science-to-business marketing model in the $\mathrm{QH}$ for the specific commercialization of science.

Returning to our theoretical interest, we wish to go beyond the quite static QH models presented above. Even though previous studies have sought to encompass how a specific project unfolds, for example by pictures of how helices develop over time (see Carayannis and Campbell 2011, p. 339, Fig. 2), they do so with a focus on stable constituents which often fail to consider and analyze the uncertainty involved in the interactions that explain how the $\mathrm{QH}$ helices relate to each other differently over time. Thus, to 
complement the current debate about innovation systems and their link to academic entrepreneurship, we apply a processual approach that affords us the opportunity to highlight how multiple trajectories of becoming affect the implementation of the $\mathrm{QH}$ model.

\section{The Processual Approach}

Process theory seeks to conceptualize how things unfold and emerge in comparison to theoretical frameworks that focus on how static objects exist (Moroz and Hindle 2012). When we accept that things change, we are also enabled to better understand how things interrelate (Hjorth et al. 2015). One should thus question the stability of things by looking at flows and ongoing states of becoming (Tsoukas and Chia 2002). Works of philosophers such as Whitehead, Bergson, Heidegger, and Lefebvre have been particularly important for the development of such processual perspectives (Verduyn 2015). Moroz and Hindle (2012) remark that Whitehead looks at processes as temporal movements where reality is interpreted as moments of experience. They add that for Bergson, the duration of a process symbolizes continuity, where experiences differ from one to the next. On the other hand, Moroz and Hindle (2012) highlight that Heidegger emphasizes how individuals are active and immersed in their environment. Whereas, Lefebvre's processual point of view is on "how the course of things changes" (Verduyn 2015 , p. 640). Fundamentally, these theoretical perspectives on processes help to explore the "how" of particular outcomes, to understand how change is created, and to follow the ontology of becoming as a result of a transformational process (Moroz and Hindle 2012).

The processual approach has been applied in explanations of the emergence of entrepreneurial ideas (Fletcher 2006): to look into the characteristics of social entrepreneurship (Perrini et al. 2010), to know how new social ties are formed and managed (Chabaud et al. 2012), to discuss the dynamics of social networks (Hoang and Antoncic 2003; Lamine et al. 2015) and networks of innovation (Farinha et al. 2016), to address the importance of weak ties for incremental innovation and strong ties for radical innovation (Elfring and Hulsink 2003), and to understand their transformation for value exploitation (Lechner and Dowling 2003). Importantly, these studies apply the processual approach differently. They mainly address social networks, which are linked to $\mathrm{TH}$ and $\mathrm{QH}$ collaborations seen to consist of a set of actors and a set of relationships (Hoang and Antoncic 2003). Similarly to how social networks are defined, Chua (2002) describes social interactions as "the impersonal configurations of linkages between people or units" or personal relationships individuals have developed through time, such as friendship (Chua 2002, p. 376). In other fields, interactions have been studied as actions that affect the actions of others (e.g., see Manski 2000). In the same way, we refer to interactions as fundamental to how a process unfolds in the case of a QH configuration.

An analytical focus on interactions is becoming increasingly important in knowledge production about academic entrepreneurship and collaborations for commercialization. Especially in $\mathrm{TH}$ and $\mathrm{QH}$ settings, interactions are part of the dynamic relationships that evolve as actors interchangeably take the role of the other, for example, through joint ventures. However, $\mathrm{TH}$ and $\mathrm{QH}$ literature has only loosely explored interactions 
processually, while several studies on social networks and collaborations address the importance of relations between actors. Kolehmainen et al. (2016, p. 27) highlight that "the actual processes and dynamics of regional development have remained surprisingly veiled."

Furthermore, Lamine et al. (2015) suggest a dynamic perspective and an integrative view to understand the entrepreneurial process through looking at its ongoing interactions. The process involves not only the creation of knowledge and value, but also the actions that take place over time. Bygrave, for example, defines the entrepreneurial process as involving "all the functions, activities and actions associated with perceiving opportunities and creating organizations to pursue them" (Bygrave 2010, p. 2). Similarly, Gartner (1985) argues that entrepreneurs are involved in a multidimensional process of organizational emergence. The study of entrepreneurship must rely on the study of "the process by which new organizations come into existence" (Vesper 1982 cited in Gartner 1988, p. 21), as new organizations are not spontaneously created; they evolve over time (Gartner 1985). Gartner's perspective opens up for a view of the QH as coming into existence hand in hand with entrepreneurial processes. Moreover, both the wider context and micro-processes are of interest in the study of QH entrepreneurial processes. Due to the processual level of analysis, we can encompass both of these layers in the analysis of the empirical material on how the $\mathrm{QH}$ model is implemented. Analyzing the $\mathrm{QH}$ as a process can both inform us about the ongoing interactions and uncover how actors, such as regional officers, citizens, and entrepreneurs, are influencing the environment at large. A processual perspective can thus help us to analytically acknowledge interactions in their sociocultural context (Steyaert 1997) to better understand how a specific QH configuration evolves. In sum, a processual approach is useful in exploration of the details in which triple-, quadruple- or N-tuple-helix configurations unfold, i.e., how the helices involved are shaped and intermingle, greatly depending on how the different actors are produced in interactions with each other. Such an analytical focus does however require a specific research design and analytical method, which is explained below.

\section{Methodology}

The empirical base for the exploration of how the $\mathrm{QH}$ unfolds and functions is a renovation of a bridge located in Uppsala, where local authorities aim to integrate renewable energy technologies by collaborating with researchers involved in academic entrepreneurship. Access was granted to this case since the regional office contacted the university and asked for help to include innovative renewable technologies. At the same time, they also wished to address how these could be further commercialized to strengthen entrepreneurship in the region. Due to this latter wish, the main researcher could be recruited and mobilized to various sites to study how the collaboration unfolded. Since the renovation project includes not only the three helices mainly addressed in the TH model but also the general public, the case seemed particularly well suited to use for an exploration of how the $\mathrm{QH}$ model is implemented. The turn to the $\mathrm{QH}$ is also reasonable in light of the fact that Sweden has been at the forefront of implementing the helix model. For example, state agencies such as the Swedish Agency for Innovation, Vinnova, encourages TH collaborations (Jacob 2006), and as such, these "became a condition for research funding in Sweden" (Leydesdorff and 
Strand 2013, p. 1899), something the regional office and their turn to the university is testament to.

The main researcher tried to remain ethnographically explorative, but with the $\mathrm{QH}$ framework in mind. She first met the actors (people from the various organizations involved in the planning process for the Flottsunds project) at a 2-day workshop in February 2014, after which she followed the planning of the renovation closely. The study was carried out until December 2015 when the planning phase finished and the construction phase had already started. In May 2014, the project manager (from a consulting company) and the project leader (from the regional office) hosted a second workshop. During these workshops and the events that followed, the main researcher was a participant and could identify key actors for future interviews. During the research, more interviewees were selected and approached depending on their role in the bridge renovation project.

The empirical material consists of in-depth interviews, conversations, as well as participant observations (see Table 1). In-depth interviews were carried out in English and took, on average, about $50 \mathrm{~min}$. The longest interview was $2 \mathrm{~h}$ and the shortest 40 min, relying on a semi-structured interview method and dialog in order to allow the participants to speak as openly as possible. In this way, the participants can be seen to offer personal insight into the specific interactions and events that formed and transformed the $\mathrm{QH}$ setting over time. In total, 13 individuals from the university-industrygovernment and civic helices were interviewed (found in the Appendix). Some of the respondents were interviewed several times on different occasions. The interviewees were local authority representatives, researchers at the university, the CEO of Current Power AB (also a researcher at the university), the project manager and the project management assistant hired as external consultants, and citizens. Questions were, for example, asked about their main responsibilities in the project, the collaboration process among the different helices, and views on interaction with other actors. Interviews were documented and transcribed, while field notes were created regularly during the observations (64 A4 pages in total). Thirteen out of 16 interviews were audio recorded and transcribed. To secure a more open discussion with the interviewees, the remaining interviews were not audio-recorded. The interviews were conducted at the respondent's workplace, at a restaurant or their homes, convenient for a good conversation during the interview. Other types of materials, such as memos and minutes of formal and informal meetings (some produced by the main researcher, others by the regional project assistants) were also collected to gain a broader understanding of the organization of the project. The main researcher was also invited to the common project collaboration system called Ibinder, a tool for managing projects. There she could follow information related to the planning process, received notifications of ongoing activities from the participants and could communicate with those involved. The researcher also engaged in informal conversations with more than 20 civil society members, including neighbors, boat owners, cyclists, and Uppsala citizens present at the construction site and at public information meetings. Field notes were audio recorded after each conversation. These notes were also transcribed and analyzed.

\section{A Processual Analysis}

How can we understand and describe change, transformation, and becoming for a QH? By focusing on ongoing transformations rather than stability, researchers can learn 
Table 1 Empirical material collected

\begin{tabular}{ll} 
Data source & Participants and affiliation/event description \\
\hline In-depth interviews & $\begin{array}{l}\text { Researchers at Uppsala University, researcher-CEO Current Power Sweden } \\
\mathrm{AB}, \text { local authority representatives from the regional office, project manager } \\
\text { and project manager assistant from consulting firms, and civil society } \\
\text { members. }\end{array}$
\end{tabular}

Conversations

Civil society members encountered near the Flottsunds' site (Jul.-Aug. 2015).

Participant observations

Flottsunds Bridge workshop

Formal meeting at Uppsala University

Boat trip to the Flottsunds Bridge site

Land and Environment Court pres

Informal meeting

Informing the community

At the site-construction phase

Shadowing
Approximately 40 people involved in the project participated: consultants, researchers, regional office representatives, and internal facilitators. Activities were organized over the course of 2 days so that the participants could get to know each other (Feb. 2014).

Researchers from Uppsala University, researcher-CEO of Current Power Sweden $\mathrm{AB}$, and regional office representatives attend the meeting. The discussion was about grant applications for the marine current turbine (Feb. 2014).

More than 30 people attend, those involved in the project from university-industry-government helices. The project manager and project manager's assistants organized the trip and a workshop together with the regional office facilitators (May 2014).

Formal presentation with Uppsala city alderman, lawyers, technical advisors, the project leader and project manager assistant, a scorekeeper and civil society members, among others. The aim was to present the bridge project to the Court for its evaluation and further authorization (Mar. 2015).

An informal lunch with some of the consultants and the new project leader from the regional office near the Flottsunds' Bridge site (Mar. 2015).

The information meeting was at Sunnersta School, located near Flottsund's Bridge. The aim was to inform citizens about the renovation project. Approximately 50 people attended (Sept. 2015).

Multiple observations at the bridge site, as the construction phase started (Oct.-Dec. 2015)

The day started at the regional office, and continued at the construction site during the daily activities of the project leader (Dec. 2015).

about "the micro-processes of change at work" (Tsoukas and Chia 2002, p. 568). By using processual thinking focused on ongoing change, it is also possible to understand how a plan for commercialization is translated into action, and in our case, how a model is implemented, modified, and changed. If organizational change is viewed as something fulfilled and final, its dynamic and emergence would also be lost from view (ibid). So instead of outcomes-based processual explanations built backwards with focus on causes and consequences, event-driven explanations that are built forward illustrate emergence by a focus on how things change over time (Moroz and Hindle 2012). We choose to use event-driven explanations since we had the opportunity to study the proposed initiative from the beginning when the outcome was unknown. Tsoukas and Chia (2002) propose to address ongoing process as a stream of interactions, and a flow of initiatives rather than a set of episodic events. They argue that "the more "positions" we identify in an object's movement, the better we describe its motion" (p. 571). However, it does not matter how many of these positions are represented because these will not capture movement. It is what goes on between 
these positions that represent change. Hence, the authors suggest, that it is by "knowing from within" that we can appreciate movement, flow, and continuity (p. 571). However, for practical reasons, researchers must choose from those endless flows and select significant events relevant for such changes to be captured. Similarly, Steyaert (1997) suggests the use of events, together with process language and dilemmas, to concretize a processual approach. First, words such as "emergence," "evolution," and "variation" influence the way we think about the entrepreneurial process. Second, to follow the process is to describe the dilemmas that emerge. Lastly, the "consecutive stream of events and interactions" is central to developing a process view (p. 19). Events, when interpreted as decisions in organizations, form points in time that bring about consequences for later events (Hernes and Bakken 2003). However, events can also be "composed of tempo-spatial experiences, rather than things of substance, such as material or human actors" (Hernes 2014, p. 6). By following events, it thus becomes possible to explain why organizations evolve in certain directions (ibid). Pettigrew also suggests that processes should be studied by the following of not only individuals, but also of collective events, actions, and activities "unfolding over time in context" (1997, p. 338). As such, one can explain how things persist, and how some configurations become stable, whereas others do not (Hernes 2014).

Hence, to study processes, some scholars use either a processual narrative approach, or variance (causal) theories (Moroz and Hindle 2012). In this particular article, we turn to Czarniawska's narrative approach, by which we aim to explore "how come" the technology that was to be commercialized was excluded. A narrative is a mode of knowing; it provides a rich source of insight (Czarniawska 2004, pp. 6-10). Narratives can thus be understood as constructed empirical material consisting of interrelated events and interactions among the research participants represented by the researcher as a narrative. We thus construct the narrative from the collected interviews, conversations, observations, field notes, and meetings. By bringing these together in a meaningful way, we attempt to better understand how the $\mathrm{QH}$ and commercialization unfolds. Importantly then, our study of the $\mathrm{QH}$ as a process implies that we apply a "constructionist view of reality" (Steyaert 1997, p. 23), where we co-create the reality under study.

Last, but not least, in conducting processual research, ethics is especially important because there are close links between the researcher and the participants or the host organizations (Pettigrew 1997). We therefore followed The Swedish Research Council (Vetenskapsrådet)'s guidelines, suggesting that the researcher must be respectful to the research participants' ideas and take measures to prevent sensitive personal information from being spread (2011, p. 70). The interviewees are thus anonymized, even if the contextual descriptions may make it possible to associate certain answers or activities with a specific individual. We did therefore carefully select the quotes and episodes and looked for integrity-sensitive information to be considerate to those involved without compromising the research findings (see 2011, pp. 65-71).

\section{The Making of a Quadruple Helix Configuration in the Flottsund Project}

The Regional Development Office (Kontoret för Samhällsutveckling, referred to as the regional office) at Uppsala municipality took the initiative to renovate the Flottsunds Bridge. A number of bridges have been in place at Flottsund (south of 
Uppsala) since the 1600s, and the existent bridge was inaugurated in 1924. It has since then been renovated several times (Flygt 1995, pp. 106-108). The bridge, which is the southernmost crossing over the River Fyrisån with ca. 5000 vehicles per day, is in exceptionally bad condition. After having studied different options, the municipality decides to build a completely new bridge at the same location. The project is among the most important construction projects carried out in Uppsala. The regional office did not only wish to improve local transport and accessibility for bikes and pedestrians, but also to implement renewable energy technologies to make the operation of the bridge more sustainable, as well as attract "green" visitors to the area. Moreover, at the Business and Development (B\&D) department, at Uppsala municipality, there is a constant search for new ideas to promote businesses and innovation in the region. The renovation project was thus combined with the goal of supporting innovation and commercialization of renewable energy within the region.

\section{How Is the Technology Introduced?}

When the discussion of the Flottsunds Bridge began, local authority representatives looked for some innovative renewable energy technology to integrate in the renovation project. The initial project leader at the regional office was particularly interested in integrating sustainable energy solutions in the renovation project. Thus, he contacts a professor from the Centre for Renewable Electric Energy Conversion at Uppsala University (UU) to initiate a collaboration. The professor proposes that UU could contribute with expert knowledge about the river flows as well as a technology for producing electricity from marine currents. The technology uses a vertical axis turbine and is not yet commercialized, but is conceived as suitable for the renovation project since free-flowing water from the river could potentially generate electricity to power the mechanics of the new bridge. The research group is also a beneficial party to be involved in the project given that the Flottsund's site would make it possible to extend the academic research with tests of the turbine in real conditions. There is already an experimental test station for the same technology at another site, Söderfors, located ca. $90 \mathrm{~km}$ north of Uppsala. However, the Flottsunds Bridge renovation project is of further interest due to the fact that the electricity produced from the turbine could be used to power the bridge functions, raising it up and down and lightening it up in the evening. As one of the researchers at the university states:

The Söderfors site provides real conditions to see all the difficulties from an engineering, scientific and planning perspective. However, there is no grid connection there, because there is no opportunity i.e., there is no project, the electricity produced is burned and not used [in the same way] as it is expected at the Flottsunds Bridge (Resp 1, Researcher).

Research on electricity generation from underwater currents has been conducted at the university since 2001. In 2004, the vertical axis concept won third place in a business plan competition, after which a limited company was set up. A year later, in the spring of 2005, the CEO, then a doctoral student, founded Current Power Sweden AB together with a few other colleagues. The spinoff company applied for a patent, which was accepted, after which the company has sought to 
commercialize the marine current power technology. However, it was not until 2013 that the first prototype generator was deployed in Söderfors, tested, and verified. Thereafter, Current Power AB did some preparations and a preliminary design dimensioned for the Flottsunds' turbine to start collaborating with the regional office. However, most of the work on the technology has so far only been pursued at the university. So far, the company is mostly handling the administration of the patents. Meanwhile, the CEO recognizes the renovation of the bridge as an opportunity to start commercializing the technology. Usually, a contract between the parties (government-university-spinoff) is needed to begin the collaboration. Instead, the regional office offers research funding on a monthly basis for doctoral students, and pays for research activities at the university without more than a shortterm research contract. The plan was to deliver an energy conversion unit for the Flottsunds Bridge and test the prototype and commercial system in real environmental conditions.

The plan was for Current Power to deliver a turbine and generator suitable for the Flottsund [project], and that it would be connected to an electrical system, with energy storage and possibilities to do studies, research on the storage and the electrical system, the whole system (Resp 3, Researcher-CEO).

The purpose of the innovative Flottsund project is to constantly retrieve electricity from the marine current power turbine and either store the energy in a flywheel or some batteries, and maybe together with additional renewable resources, such as wind and sun, to power the bridge. The aim is also to develop entrepreneurial ventures in the region, and develop the technology further as an alternative energy source.

One benefit is to try to develop new technology because there are small-scale and large-scale possibilities for this technology. There is interest from farmers, for instance, who want to utilize this kind of technology to be energy self-sufficient (...). If that could be done we could create new companies that can exploit this technology. The primary goal is that we can help research going forward and we can also show that there are alternative solutions (Resp 4, Local authority rep).

The purpose of this technology would not [be] to produce on a large scale, unlike nuclear power, [but] more meant to be a complement for everything else and harness the energy that we are not using. It could be part of these smart electrical grids that will incorporate local production (Resp 1, Researcher).

A group of consultants are also part of the collaboration as they were hired by the regional office to work on the design of the new bridge. The consultants manage the project in cooperation with the project leader at the regional office. The team deals with different requirements from various authorities and civil society, particularly some area residents. In sum, an interactive configuration emerged from the regional office 
initiative, with the aim to collaborate with the university, where more actors became involved in the process.

The Flottsund project encountered plenty of unforeseeable changes and uncertainties during the following year. In early 2015, a new project leader is assigned at the regional office (informal meeting, March 2015) and another one after him, at the same time as a new budget is put in place. The regional office that is funding some of the research activities at that time, realizes that the marine current power turbine could not be financed entirely by them, as pointed out:

We realized that the technology couldn't be financed as an ordinary business case. I mean you need to have payback time in a certain number of years (...) you have to treat this more as a research project. That is when we agreed to search for external financing, and further agreed that the university should be the one that seeks out or tries to get external financing (Resp 4, Local authority rep).

Consequently, the university stops receiving funding from the regional office for the research project. The new project leader's main responsibility is the overall project economy, which had previously been suffering. As is common for projects like this one, the budget was initially lower. In addition, the initial project leader had been personally engaged in renewables and saw a potential commercialization of them as a very positive "green" contribution to the renovation of the bridge, as well as to Uppsala more generally. Nevertheless, these renewables were not included in the initial budget for the bridge, which is why the new project leader now has to take control of the budget and overall situation, and prioritize the project's execution, and this includes more focus on bringing the citizenry on board, as recalled:

There is some pressure from the citizens to build it right away; the bridge [the construction phase], will start in August or September if the court rules in our favour (...). The regional office has a bad reputation, like if we don't do anything, we are lazy, everybody has an opinion here in Sweden that the regional office is a safe haven for people who don't like to work (...). So we have to get everyone on board, including the newspapers and all of that so we can build this bridge in a good way (Resp 6, Local authority rep).

\section{How Is the Fourth Helix Included?}

A budget of about two million SEK was set up for communication with the populace of Uppsala. It includes banners around the city, information in the newspapers, online communication on the regional office website, flyers and meetings regarding the Flottsunds Bridge information as seen in Picture 1. The slogan used for the bridge is "Flottsundsbron: New bridge - better environment" (Flottsundsbron: Ny bro - bättre miljö). A first meeting is arranged with people living next to the bridge. The project leader gives a presentation and explains that it ended up like a one-way communication with a feeling that several angry questions were posed. "I felt like a target", he emphazises (Resp 6, local authority rep.). In 
September 2015, a second meeting is organized to give more information about the renovation project and to include all of Flottsund's closest community (Informing the community, September 2015). This time, the regional office is trying out an open format that could help to create a dialog, with tables in the room and different stands where people could talk in smaller groups, or one to one with local authority representatives. Most of the participants who attend live around the area; others are representatives from shipping lines and sailing clubs. The project leader is very active explaining and giving information about the renovation schedule and technicalities. People are interested in knowing about the noise during the construction phase, traffic issues, summer schedule for openings, and potential damage to their houses, but not much interest is on the renewable energy technology. We therefore approached the project leader and asked him about the renewable technology explicitly. He explains and shows us that preparations were made for it in the drawings of the bridge as seen in Picture 1. A base plate for a 15.00-m turbine (Bottenplatta for Turbin $15.00 \mathrm{~m}$ ) is specified in the architectural plan. He further explains that the talks between the local authorities and the professor were ongoing, and according to him, the negotiation was moving forward.

The project manager who was hired by the regional office is making plans for the project and is responsible for managing its execution, whereas the project leader is the one responsible for the overall project within the regional office. Their task is to handle complexities that arise, which they see as highly demanding. Part of their job is to invite citizens to a dialog, provide information, and cope with their requirements. The project manager and project manager assistants, for example, organized a couple of meetings at the beginning of the project to address the community concerns where they also informed them about the renewable energy technology to be placed in the bridge, as pointed out:

They [the citizens] know that because we are preparing for this renewable energy tech, because we are building a concrete platform at the bottom of the Fyrisån, where it will be placed (...), we have [in the design] a special [space] for Uppsala University to have machines and where they can study the turbine, so all is set for them to come and install the technology; and therefore we have all this information when we are talking to people about the project. There was some interest in the new energy technology, but still the focus is on the bridge and how it will affect those living nearby (Resp 9, Project manager assistant).

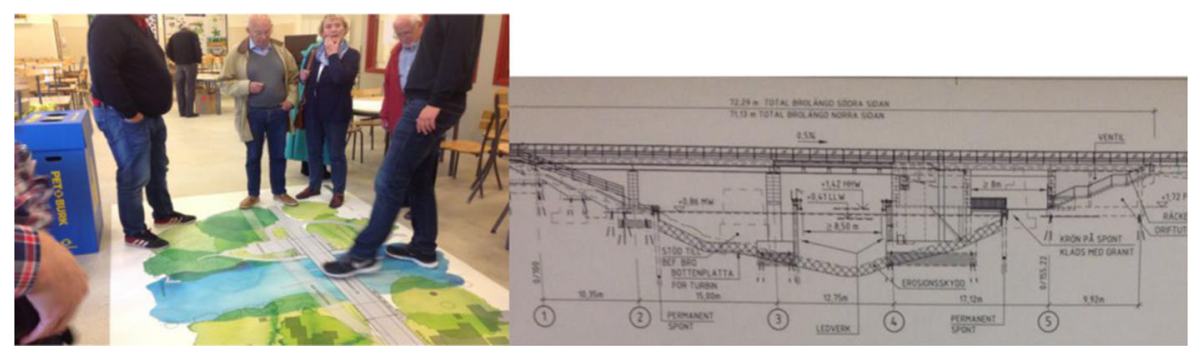

Picture 1 Uppsala citizens and regional office representatives in a meeting, and the architectural plan for the Flottsunds Bridge, which includes a base plate for the turbine (Informing the community, September 2015) 
Originally, the neighborhood of Sunnersta, which includes the Flottsund area, was dominated by vacation homes. The Flottsund area is the part closest to the bank of the River Fyrisån. Some residents live there only during the summer, whereas others live there all year around. Today, it is considered to be a peaceful neighborhood and instead of promoting the renovation as a renewable energy project, with a self-sufficient bridge-opening device, the regional office chose to promote the renovation as an upgrade of the area as a recreational space. This betterment of the local environment is directed at the citizenry. However, in the beginning, when the university was contacted about the integration of renewable energy, the regional office wished to make that into a specific tourist attraction.

During the study of the fourth helix, we encounter various stories about the bridge. For example, additional space is needed for the preliminary bridge. There was not enough land on one of the riverbanks, which is why the project manager and regional office representatives negotiate with some of the citizens who lived next to the renovation site. After some time at the site a boat comes, the traffic controller officer is standing on the bridge; he opens the bridge for the boat to pass. He mentions that it is an old bridge and sometimes he needs to re-start the mechanism to open it when it gets stuck. With the new bridge, he will be able to remotely operate it and therefore will not need to be present at the site (Fieldnotes). Moreover, the regional office also accounts for the bridge's historical background to define its aesthetics and design. During the planning process, it was decided that the old abutment, made of granite that holds up the old bridge, should be reused for the new bridge. This was thought to preserve some part of the bridge's cultural heritage from the nineteenth century. There is also a nature reserve on both sides and the locals do not want a massive bridge; they want something conservative that does not intrude on nature, according to the project leader (Resp 6, local authority rep). A couple that lives next to the bridge also sold a part of their land to the municipality. Their main issue is that they use their garden to park their own vehicles. However, since the bridge is extended toward their garden to include cycling and pedestrian paths, they might not be able to do so. The bridge is from 1925 and has some vibrations; the neighbors agree that it needs to be renovated; however, they seem to dislike the communication process with the authorities, as mentioned:

They [the regional office rep] don't care. They informed us, show us some maps and drawings and everything will be done, but there is nothing we can do (...) we don't like it because the bridge will be elevated and probably you could see our garden from there. We don't know (Fieldnotes).

Other neighbors similarly complain about the miscommunication with local authority representatives, as mentioned:

They don't inform us of much and I think the feedback process has been very bad. If you raise a question, you would really like to have a response, so that I saw you, I heard you, here is the response but nothing like that has happened yet (Resp 10, citizen).

There are other people in disagreement with the renovation plans. For instance, members of a boat club are concerned about being able to sail and exit the river during 
the renovation time, which, according to the initial plans, looked very difficult. Shipping line representatives are critical to the plans since they feared they would lose many customers during the summer season. The M/S Kung Carl Gustaf boat's owner thus argues for more opening times. This boat has been operating in Uppsala for more than 26 years now. The compromise is therefore to lift a part of a preliminary bridge, to be provisionally built next to the site, by using a crane a couple of times per day for the sailboats and tour boats, so that they are able to reach open water. This solution, however, causes both delays and a higher cost for the regional office.

\section{How Is the Technology Excluded?}

In parallel to the communication with the citizens, the regional office continues with the planning phase. While waiting for the university's external funding, the regional office representatives, along with the consultants, keep working on getting permits and approvals from other agencies. In March 2015, a risk assessment for the renovation project is presented to the Land and Environment Court (Mark-och miljödomstolen) (Land \& Environment Court pres, March 2015). Uppsala city alderman, lawyers, technical advisors, the project manager assistant, a scorekeeper, and civil society members participate. A formal meeting takes place, followed by specific questions mainly from the alderman. The general public could also post questions and briefly comment on the plans. At that stage, one notable concern is a potentially increased level of the water in the river caused by the new bridge design. Due to this risk factor, it is also conceived as too complicated to negotiate yet another feature to the design. Hence, the marine current turbine is excluded from the risk assessment report to make the case as simple as possible. The regional office gave a detailed report beforehand to the technical council to authorize the project. The regional office does furthermore believe that including the turbine could compromise the project's approval, since there was already uncertainty related to the operability of the new bridge and its potential influence on the surroundings. Thus, local authority representatives argue that there is a critical period to get approval from the court to start building the bridge, and decide to remove the information related to the turbine from the risk assessment to not jeopardize the entire project. This is by extension problematic for the university researchers since they will need to go through the evaluation process and present a risk assessment of the turbine by themselves to install the turbine later on. Hence, even though the regional office aims to have the marine current power turbine included in the Flottsund Bridge, the regional office argues that they could not pay for the technology. Thereafter, the university worked on funding applications with a positive response from one of the agencies. When the academic entrepreneurs were close to receiving funding to build the turbine, the regional office representatives fizzled out. The reason was that the project leader at the regional office was uninformed about the research application, and surprisingly told the potential funders that there was no existing collaboration with the university. The grant application did however outline a QH model approach, to be taken together with the regional office as representatives for the "government helix". This is a major drawback for the project as no money or support reaches the marine current turbine for the Flottsunds' site.

With time, the interactions between the regional office and academic entrepreneurs decline, and the implementation of the renewable energy technology, becomes more 
and more distant. In addition to the problems with funding, there is an issue with timing:

It seems it [the collaboration] will not get better, because now it is March (2015) (...) they are going to start building the bridge in October and we need some time to build the device so we could place it below the bridge before the bridge is ready (Resp 2, Researcher).

On the other hand, the Flottsund project continues as the regional office finally gets approval from the Land and Environment Court after a second evaluation. Afterwards, with all the necessary permits, a procurement process follows. Hereby, contractors could be chosen and the renovation could proceed to the construction phase (At the site - construction phase, October-December 2015; Shadowing, December 2015).

\section{Analysis - a Processual Approach for the Helix Model}

We will now look closer at the stream of interactions and flow of events in the narrative above. We will address how the micro-processes of the actors are linked to the broader context, to describe how the helices sometimes merge and sometimes are drawn apart. Even if the emergence of the $\mathrm{QH}$ and the collaborations that underpin it are to be understood processually, we have chosen to create a few clarifying illustrations. Figure 1 of the $\mathrm{QH}$ is based on the narrative and is more processual in comparison to the $\mathrm{QH}$ model in Fig. 2. These should not be interpreted as static positivistic representations of "reality," but as pedagogic tools that function as a backdrop to our exploration of how the QH unfolds with a focus on how the technology slowly was excluded and the commercialization was inhibited. From the helices' intersections, the regional office and the university/spinoff initial interactions, the consultants' involvement, and civil society participation, we will now provide a more explorative analysis of the unfolding $\mathrm{QH}$.

\section{The Intersection Between the Regional Office and the University/Spinoff}

The QH emerges from the regional office's initial effort to integrate renewable energy into the construction of the bridge and the proposed collaboration with the university, as in Fig. 2, QH (a). Above, the illustration (Fig. 2) of the unfolding collaboration between

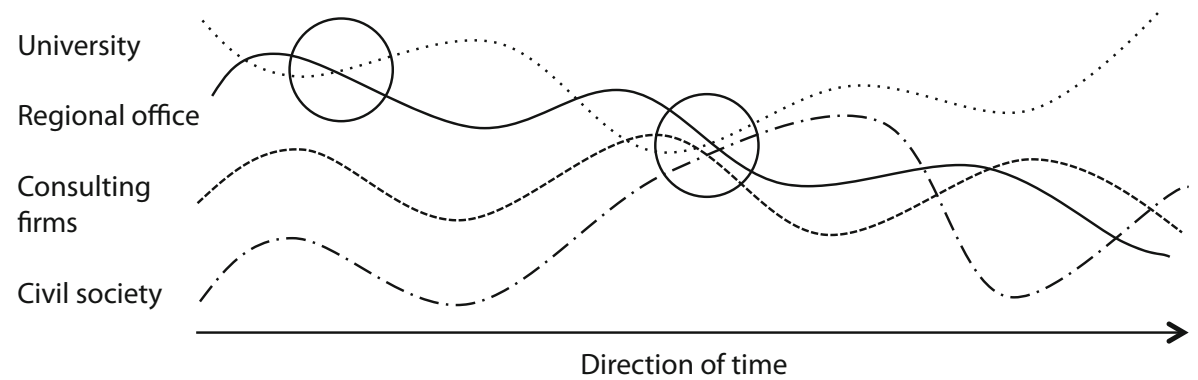

Fig. 1 A processual portrait of the quadruple helix based on Carayannis and Campbell (2009, p. 207) 


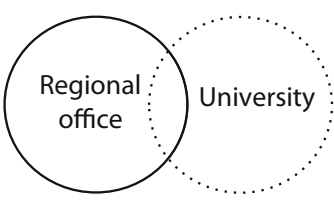

a

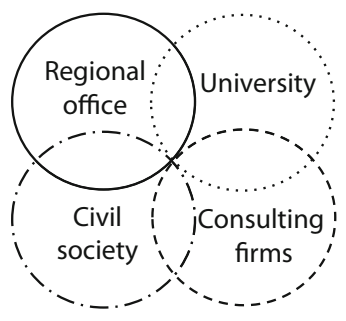

b

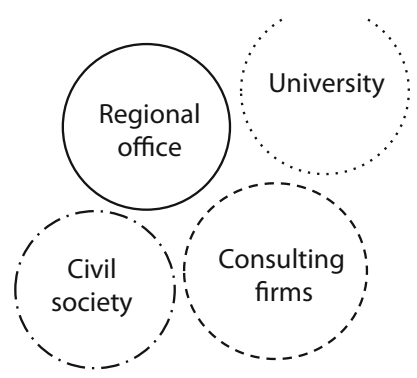

C

Fig. 2 The quadruple helix, which illustrates how the collaboration emerges (a), unfolds (b), and how it evolves (c)

actors in the different helices shows that the ambition to integrate a renewable energy technology in the renovation project changes throughout the process. The project path moves and changes by certain means and people (Tsoukas and Chia 2002). One such person is the very first project leader at the regional office who has a personal interest in environmental issues. The inclusion of renewable technology therefore becomes a key event that changes the path of the planning process. The rhetorical means that changes the direction of the process is an announced wish to make the bridge self-sufficient and possibly to come across as "green" to the general public. And as we know from the narrative above, the regional office had no specific budget for the technology, but wished to communicate the greener alternative with civil society. This is something that processually brings the fourth helix closer to the regional office. In this article, we thus include the green environment in the fourth helix, since we wish to study how it is spoken about and included in the innovation system by human actors. Researchers who also act as entrepreneurs are thus invited to attend meetings with local authority representatives. First to share information about the technology where I could observe an "overlay of negotiations and exchange relations" (Leydesdorff 2003, p. 450) that affected the micro-processes. At this point, there is a vision (a shared vision, at the initial workshops involving different stakeholders) of the $\mathrm{QH}$ model as consisting of four nicely interacting helices, as in the QH (b), in Fig. 2. However, since the ambition of the regional office is more politically driven than economically viable, the researchers have to find their own funding for both manufacturing the turbine and for the research activities. Hjorth et al. (2015, p. 600) argue that "through time, there are breaks in coherence or consistency" of the patterns, such as mergers, changes, histories represented, due to the various groups' different interest and desires. Similarly, Grundel and Dahlström (2016) argue that different actors also have different aims and goals making it difficult to collaborate. For example, governments usually build their judgments on development and growth agendas, whereas academia focuses on the exchange of ideas and knowledge. In the same way, interests differ over time within the regional office and university helices. The regional office representatives tend to judge the collaboration more in terms of competitiveness and regional development, whereas the researchers aim for the transfer of knowledge and technology, i.e., to test the technology in real conditions.

Uncertainty with receiving grants is a fundamental part of how the QH unfolds. After the first applications for funding had been sent, there is a lack of communication 
between the regional office representatives and the researchers. That is, the static $\mathrm{QH}$ model, as in the QH (b), in Fig. 2 with helices functioning in an interactive way, crossing each other, now looks like separate helices, moving along their own processes and unknown paths, as in the QH (c), in Fig. 2. The helixes are configured continuously and are "not fixed or even definitive, but evolving multiply as people create and are created by the roles and identities they inhabit/perform and by the practices they enact" (Hjorth et al. 2015, p. 603). As such, the regional office representatives create a distance between the helices, by speaking about reasonable payback times and other criteria that are far from the reality of the university and spinoff helices. Prónay and Buzás (2015) highlight that intellectual property produced at universities typically enter in the initial phase, with considerable risk attached to them. The patent on the marine turbine is an early step in the commercialization process; however, the price and other values such as future profitability and payback times are difficult to set since it is a new product. The researchers also distance themselves from the regional office by not attending all the meetings. On the other hand, the university and spinoff are now merged and move forward in the process together, as the researchers/academic entrepreneurs are taking over the responsibility for funding applications and wait for approved funding to become more active in the commercialization process.

Startup competitions may help academic spinoffs gain visibility, which can help them to have access to valuable resources (Parente et al. 2015). In the same way, after winning third place in a business plan competition, Current Power AB was set up with the funds that it got from the competition. Winning a competition may be "the first time for researchers to convert their own research into an entrepreneurial project" and an opportunity to communicate the project to civil society (ibid, p. 555). However, winning does not necessarily increase the rate of success of those winners, and actually the rate of success is very low (ibid). This is mainly because these competitions focus on "broadcasting the research and entrepreneurial commitment of academia rather than going into detailed business analysis of the entrepreneurial projects" (ibid, p. 563). Thus, even though the spinoff gained legitimacy through the startup competition, the researchers/academic entrepreneurs must account for the expectations from business, and moreover from the society, for the application of knowledge (as suggested by Prónay and Buzás 2015).

\section{The Intersection Between the Regional Office, the University, and Consulting Firms}

Another junction of helices is located between the regional office, the university, and consulting firms. To begin, regional office representatives work closely with the consultants in the planning phase. A communication plan including an online platform to exchange documents, frequent face-to-face meetings, and workshops, allows the consultants to coordinate relatively well with the regional office representatives during the process. However, for the researchers, it became difficult to communicate with both the regional office representatives as well as the consultants. One reason is that it takes time to understand how the technology works and what the technical needs are to fit those into the design even though the local authority representatives were interested in the collaboration as they initiated it. On the other hand, the consultants questioned the integration of the turbine. The consultants previously expressed their uncertainty related 
to an early-stage technology and its potential value. Accounting for potential factors such as how the innovation is connected to the creation of social value, such as studying the long-term effects of the technology, may influence the marketing of innovations (Prónay and Buzás 2015). In addition, a more interactive, open and involving information flow, and aligned solutions, are essential during the process (ibid). The consultants also distance themselves from the researchers as they expected the researchers, acting as technical experts, to take on more responsibility in the project. Prónay and Buzás (2015) recommend a professional business-like attitude among researchers and a real entrepreneurial university model for the commercialization of science. Moreover, the project manager claims that there are very different ways of working among them (consulting firms - university helices), which is why communication barriers makes their coordination unbalanced. As mentioned, academia aims for the creation and transfer of knowledge, whereas "firms and business tend to build their judgments on market principles" (Grundel and Dahlström 2016, n.p.). In the same way, the consulting firms focus on the efficient use of resources to build the bridge on time and on budget, whereas the university aims to test the turbine and the whole system under real-life conditions. In sum, the initiative from the regional office to work with the university became difficult, not only due to a lack of funding, but due to the fact that the collaboration was not entirely supported by an active dialog among the various actors, whereby different expectations collided. Aranguren and Larrea (2011) state that tacit knowledge is key to innovation, and it can be transferred only in face-to-face interactions. On the contrary, the regional office representatives met frequently with the consultants, whereas the researchers communicate with the other actors mostly through emails, making it difficult to share specific information about the technology or the status of the funding applications. Kolehmainen et al. (2016, p. 30) recognize that it is only through "personal interaction, in addition to the structural level connectivity of the organizations", that one can achieve a shared vision. The consulting firms - university helices could improve their personal relationships through an interactive communication to ensure an alignment among the actors (Di Nauta et al. 2015). It is important as well "to constantly renew goals and processes" (Aranguren and Larrea 2011, p. 574), i.e., to define and redefine them among the participants themselves in order to develop mutual understanding. As such, the helices must adapt to changes within the project but also within their own organizations as people come and go along the planning phase. Plans are translated into actions (Tsoukas and Chia 2002) by different actors and are constantly changing, thus the importance of renewing goals and processes. As new people join the project and new dilemmas emerge, the actors must communicate well to ensure continuity within the project and cooperation among the various helices.

\section{The Intersection Between the Regional Office, Consulting Firms, and Civil Society}

In the following junction of helices between the regional office, consulting firms, and civil society, the interactions differ. The intermingling between the regional office and the consultants starts off being merely contractual. However, as the consultants' became more immersed in the process of planning the construction, they also connect more closely with the regional office. The consultants deal with and manage issues that can jeopardize the project's execution. For example, the project leader from the consulting firm acknowledges the neighbors' complaints and is helping to mediate 
between the regional office and the fourth helix, consisting of the citizens affected by the bridge renovation. Overall, this communication with the fourth helix is one way, as the consultants do not aim for an exchange of knowledge, ideas, or feedback loops in a democratic way (Campbell et al. 2015). They procure civil society participation, to secure commitment and acceptance on the decisions already taken, as frequently practiced by major consultancy firms (Strannegård and Styhre 2013). Turning to the renewable technology, it was not a focal point for the consultants during the information meetings with the citizenry. This is not a surprise, since the primary questions broached at the meetings related to the bridge dimensions, aesthetics, and construction times. The consultants also acknowledge that the construction plans and the executed plans differ, and, to some extent, constantly modifies. This is one of the reasons why they meet with the regional office representatives only when needed, in an attempt to limit them from changing and shaping the plans, which, over the course of the process, are altered in seemingly unpredictable ways.

Regarding the renewable energy technology, there was no significant action from citizens to include the turbine in the bridge. However, members of civil society play an important role since they help to shape the renovation project in various ways. The communication becomes more fluent between the regional office and civil society. For example, the citizens wished for the construction of a preliminary and provisional bridge in the same location and also members of a boat club influenced the preliminary bridge's opening times for boats to cross over during the summer. To overcome the obstacle of informing different stakeholders, the regional office uses media and organizes meetings. However, the engagement with the fourth helix could have been performed earlier, as they felt left out of the decision-making process. As suggested, a strong active dialog with citizens, through ICTs for example, could influence the innovation ecosystem (MacGregor et al. 2010), where civil society actively demands innovative goods and services and participates in the process (Afonso et al. 2012). Carayannis and Campbell (2009) discuss the "pluralism of knowledge modes" (p. 206), and refer to how knowledge, innovation, and democracy interrelate. Democracy assumes a possible balance between different parties, values, and policies, recognized as necessary for a QH innovation system to exist (Campbell et al. 2015). Hence, a democratic context that considers the fourth helix ideas and interests should be considered early if a QH innovation-friendly ecosystem is desired (Casaramona et al. 2015). Otherwise, it can become fragmented, as this study of a QH collaboration shows (c), in Fig. 2.

\section{Conclusions}

In this paper we have addressed the implementation of the $\mathrm{QH}$ model, used for the integration of renewable energy technology in the renovation of a bridge in Uppsala, Sweden. The regional office wished to facilitate the testing of a new technology in real environmental conditions, which is needed to speed up the commercialization and penetration of new technologies within renewable energy (Casaramona et al. 2015). However, the plans to do so failed during the process. By using a processual theoretical perspective with an empirical focus on the interactions and events, we have explored how the micro-processes at play affected how the different helices unfolded over time, 
and by extension, contributed to an exclusion of the technology. By showing the dynamic, unfolding, and emergent qualities of the $\mathrm{QH}$, we thus contribute to knowledge about failed collaborations. Similarly, Jensen and Tragardh (2004) recognize that the TH collaboration can fail due to the various actors' many goals and different interests, but point out that negative outcomes are scarcely addressed. They show how, in weak regions, economic growth can be reached through $\mathrm{TH}$ cooperation, but more difficult to manage and implement, as we have illustrated in detail in this study. Jensen and Trädgårdh argue that one reason for failures is that the $\mathrm{TH}$, when implemented in weak regions, does not account for the civil sector. Though, we argue that this is not only true for weak regions but also in supposedly stronger regions, such as Uppsala, where there are well established links between academia and the governmental sector (Danell and Persson 2003).

The findings confirm that funding is important for new renewable energy technology to be further commercialized, as argued, "in the helix model, the financial aspect is a relevant element for the development of new businesses" (Colapinto and Porlezza 2012, p. 350). Nevertheless, a functioning communication among all the different actors represented in the helixes underpins all other aspects, and especially the financial, as our study shows. We found that the translation of a distinct technical language among the different actors was crucial, for the new regime not only to emerge, as recognized by Leydesdorff and Etzkowitz (1996), but also to create a shared vision. This translation never happen, and expectations were never aligned and the actors never came to share assumptions about the mission, purpose, levels of interaction, and project goals. Carayannis and Campbell (2009, p. 225) note that interaction "economises on precisely the factors on which humans are short, such as time and understanding." Thus, an active participation of scientists, like face-to-face meetings, was crucial in order to bridge the distances among the other actors. Lastly, the civil society in this particular case was offered limited information about the technology and is conceived by the other helices (regional office-consulting firms) as confronting the decision making process; even though they shaped the renovation project, civil society did not contribute substantially to the part where renewable energy was to be integrated. The fourth helix was included in the renovation of the bridge, but not in the commercialization of the renewable technology. The citizens were included as "users" (Arnkil et al. 2010), but not in relation to renewable technology, rather in relation to the area as recreational. As such, we argue that the fourth helix could have been invited to participate at an earlier stage, when the renewable technology was discussed in the planning phase. This could have added to awareness about an additional green environmental agenda in the renovation project and a more participatory democratic process around such a political agenda. However, the civil society was left out of decision-making processes (similar to Grundel and Dahlström 2016).

Further, as Lindberg et al. (2012) argue, it is important to include the fourth helix to facilitate a prosperous creative knowledge environment. If the different actors had been provided with more information about the renewable technology and its benefits, a more positive environment for experimenting and learning could have resulted (Aranguren and Larrea 2011). Fundamentally, the QH, if more properly implemented, could have encouraged a more innovation-friendly culture (Nordberg 2015; Casaramona et al. 2015). This can be achieved through an active use of media, meetings, and online platforms in a "dialogical involvement with the participants" (Aranguren and Larrea 2011, p. 575). As suggested by MacGregor et al. (2010, p. 188) "the quadruple helix intends civil society to be engaged with the other three types of 
innovation actors - government, academia and industry." This is essential not only for inclusive, but also for sustainable, economic growth (Afonso et al. 2012). In our case, however, the citizens were mostly in dialog with the regional office representatives only.

Knowledge about failed collaborations in the implementation of the $\mathrm{QH}$ can be furthered by in-depth case studies that focus on events and interactions across the four helixes. These interactions change along the commercialization process and continuously create new organizations, of which some parts simply dissolve, as in this case. Process thinking and narrative approaches can thus help us to describe and better understand such continuous formation of organizations, or, organizing in motion. Even if the $\mathrm{TH}$ and $\mathrm{QH}$ sometimes are understood as development of innovations over time, the approach in this article contributes with a more detailed processual account of how the configuration emerges and evolves. Process theory can be helpful in real-time studies of how a QH model unfolds as a process - when we do not even know the outcome of the potential commercialization. We thus propose that the $\mathrm{QH}$ model benefits from being studied in the making, in its emergence, and evolution, as "actors, opportunities and organizations are simultaneously organized and are organizing" (Hjorth et al. 2015, p. 606). This is particularly a fruitful approach in the study of $\mathrm{QH}$ for the commercialization of renewable energy, where the interactions involved are dynamic and uncertain. There is however no way around this complexity, as long as we believe in participatory processes where the $\mathrm{QH}$ setting should open up for a diversity of actors who are offered to influence the commercialization process as the work unfolds. At least, this is preferable if the expertise of the various helices is to be integrated for the advancement of knowledge-based societies and economies (Carayannis and Campbell 2011).

Finally, reflecting on our own research practice, our narrative approach has shaped the story of the failed commercialization process told. Our findings are limited to the collection of empirical material and the choice and reconstruction of events and interactions. Without being an exhaustive study of the interactions involved, we do however hope to have illustrated the implementation of the $\mathrm{QH}$ and unfolding process. Future research could delve further into the dimensions of $\mathrm{QH}$ interactions, for example, norms of cooperation, willingness to help, the level of care, accessibility of information, and degree of consensus (Chua 2002). Extended studies of these dimensions would address the growing interest in how the $\mathrm{QH}$ model emerges via citizen participation and micro-processes linked to a broader context of knowledge creation and dissemination.

\section{Appendix}

Resp 1. Researcher, interview carried out on October 16, 2014 at Uppsala University. Resp 2. Researcher, interview carried out on October 20, 2014 and March 17, 2015 at Uppsala University.

Resp 3. Researcher-CEO, interview carried out on April 29, 2015 at Uppsala University.

Resp 4. Local authority rep, interview carried out on December 22, 2015 at the Regional Office. 
Resp 5. Local authority rep, interview carried out on December 22, 2015 at the Regional Office.

Resp 6. Local authority rep, interview carried out on March 30, 2015 at the Regional Office.

Resp 7. Local authority rep, interview carried out on November 18, 2014 at the Regional Office.

Resp 8. Project manager, interview carried out on October 29, 2014 at a restaurant in Stockholm.

Resp 9. Project management assistant, interview carried out on March 12, 2015 at a restaurant in Uppsala.

Resp 10. Citizen, interviewed carried out on October 6, 2015 at Uppsala University.

Resp 11. Citizen, interviewed carried out on August 1, 2015 at her home in Uppsala.

Resp 12. Citizen, interviewed carried out on August 4, 2015 at his home in Uppsala.

Resp 13. A foundation for cooperation rep, interviewed carried out on April 8, 2015 at STUNS in Uppsala.

Open Access This article is distributed under the terms of the Creative Commons Attribution 4.0 International License (http://creativecommons.org/licenses/by/4.0/), which permits unrestricted use, distribution, and reproduction in any medium, provided you give appropriate credit to the original author(s) and the source, provide a link to the Creative Commons license, and indicate if changes were made.

\section{References}

Afonso, O., Monteiro, S., \& Thompson, M. (2012). A growth model for the quadruple helix. Journal of Business Economics and Management, 13(5), 849-865.

Aranguren, M. J., \& Larrea, M. (2011). Regional innovation policy processes: linking learning to action. Journal of the Knowledge Economy, 2(4), 569-585.

Arnkil, R., Järvensivu, A., Koski, P., \& Piirainen, T. (2010). Exploring the quadruple helix. Tampere: Report of Quadruple Helix Research for the CLIQ Project, Work Research Centre, University of Tampere.

Betz, F., Carayannis, E., Jetter, A., Min, W., Phillips, F., \& Shin, D. W. (2016). Modeling an innovation intermediary system within a helix. Journal of the Knowledge Economy, 7(2), 587-599.

Björk, P. (2014). The DNA of tourism service innovation: a quadruple helix approach. Journal of the Knowledge Economy, 5(1), 181-202.

Bygrave, B. (2010). The entrepreneurial process. In W. Bygrave \& A. E. Zacharkis (Eds.), The portable MBA in entrepreneurship (pp. 1-26). Noboken: John Wiley \& Sons.

Campbell, D. F., Carayannis, E. G., \& Rehman, S. S. (2015). Quadruple helix structures of quality of democracy in innovation systems: the USA, OECD countries, and EU member countries in global comparison. Journal of the Knowledge Economy, 6(3), 467-493.

Carayannis, E. G., \& Campbell, D. F. (2009). 'Mode 3' and 'Quadruple Helix': toward a 21st century fractal innovation ecosystem. International Journal of Technology Management, 46(3-4), 201-234.

Carayannis, E. G., \& Campbell, D. F. (2011). Open innovation diplomacy and a 21st century fractal research, education and innovation (FREIE) ecosystem: building on the quadruple and quintuple helix innovation concepts and the "mode 3" knowledge production system. Journal of the Knowledge Economy, 2(3), $327-372$.

Carayannis, E. G., \& Rakhmatullin, R. (2014). The quadruple/quintuple innovation helixes and smart specialisation strategies for sustainable and inclusive growth in Europe and beyond. Journal of the Knowledge Economy, 5(2), 212-239.

Carayannis, E. G., Barth, T. D., \& Campbell, D. F. (2012). The quintuple helix innovation model: global warming as a challenge and driver for innovation. Journal of Innovation and Entrepreneurship, 1(1), 1. 
Casaramona, A., Sapia, A., \& Soraci, A. (2015). How TOI and the quadruple and quintuple helix innovation system can support the development of a new model of international cooperation. Journal of the Knowledge Economy, 6(3), 505-521.

Chabaud, D., Fayolle, A., Jack, S., \& Lamine, W. (2012). Topic: entrepreneurial process and social networks: a dynamic perspective. Entrepreneurship and Regional Development, 24(7-8), 729-732.

Chua, A. (2002). The influence of social interaction on knowledge creation. Journal of Intellectual Capital, 3(4), 375-392.

Colapinto, C., \& Porlezza, C. (2012). Innovation in creative industries: from the quadruple helix model to the systems theory. Journal of the Knowledge Economy, 3(4), 343-353.

Czarniawska, B. (2004). Narratives in social science research. Sage, (pp. 6-10).

Danell, R., \& Persson, O. (2003). Regional R\&D activities and interactions in the Swedish triple helix. Scientometrics, 58(2), 203-218.

Di Nauta, P., Merola, B., Caputo, F., \& Evangelista, F. (2015). Reflections on the role of university to face the challenges of knowledge society for the local economic development. Journal of the Knowledge Economy, 1-19.

Dougherty, D., \& Dunne, D. D. (2011). Organizing ecologies of complex innovation. Organization Science, 22(5), 1214-1223.

Elfring, T., \& Hulsink, W. (2003). Networks in entrepreneurship: the case of high-technology firms. Small Business Economics, 21(4), 409-422.

Etzkowitz, H. (1983). Entrepreneurial scientists and entrepreneurial universities in American academic science. Minerva, 21(2-3), 198-233.

Etzkowitz, H. (2008). The triple helix: university-industry-government innovation in action. Routledge, (pp. 1, 28).

Etzkowitz, H., \& Leydesdorff, L. (2000). The dynamics of innovation: from National Systems and "mode 2" to a triple helix of university-industry-government relations. Research Policy, 29(2), 109-123.

Farinha, L., Ferreira, J., \& Gouveia, B. (2016). Networks of innovation and competitiveness: a triple helix case study. Journal of the Knowledge Economy, 7(1), 259-275.

Fletcher, D. E. (2006). Entrepreneurial processes and the social construction of opportunity. Entrepreneurship and Regional Development, 18(5), 421-440.

Flygt, B. (1995). Uppsalas tekniska historia. Kommittén för utgivandet av Uppsala stads historia, (pp. 106108).

Füzi, A. (2013). Quadruple helix and its types as user-driven innovation models. 11th International Triple Helix Conference, 1-27.

Gartner, W. B. (1985). A conceptual framework for describing the phenomenon of new venture creation. Academy of Management Review, 10(4), 696-706.

Gartner, W. B. (1988). Who is an entrepreneur? Is the wrong question. American Journal of Small Business, 12(4), 11-31.

Grundel, I., \& Dahlström, M. (2016). A quadruple and quintuple helix approach to regional innovation systems in the transformation to a forestry-based bioeconomy. Journal of the Knowledge Economy, 1-21.

Hernes, T. (2014). A process theory of organization (pp. 1-15). Oxford: OUP.

Hernes, T., \& Bakken, T. (2003). Implications of self-reference: Niklas Luhmann's autopoiesis and organization theory. Organization Studies, 24(9), 1511-1535.

Hjorth, D., Holt, R., \& Steyaert, C. (2015). Entrepreneurship and process studies. International Small Business Journal, 33(6), 599-611.

Hoang, H., \& Antoncic, B. (2003). Network-based research in entrepreneurship: a critical review. Journal of Business Venturing, 18(2), 165-187.

Jacob, M. (2006). Utilization of social science knowledge in science policy: systems of innovation, triple helix and VINNOVA. Social Science Information, 45(3), 431-462.

Jensen, C., \& Tragardh, B. (2004). Narrating the triple helix concept in "weak" regions: lessons from Sweden. International Journal of Technology Management, 27(5), 513-530.

Kolehmainen, J., Irvine, J., Stewart, L., Karacsonyi, Z., Szabó, T., Alarinta, J., \& Norberg, A. (2016). Quadruple helix, innovation and the knowledge-based development: lessons from remote, rural and less-Favoured regions. Journal of the Knowledge Economy, 7(1), 23-42.

Lamine, W., Jack, S., Fayolle, A., \& Chabaud, D. (2015). One step beyond? Towards a process view of social networks in entrepreneurship. Entrepreneurship and Regional Development, 27(7-8), 413-429.

Lechner, C., \& Dowling, M. (2003). Firm networks: external relationships as sources for the growth and competitiveness of entrepreneurial firms. Entrepreneurship and Regional Development, 15(1), 1-26.

Leydesdorff, L. (2003). The mutual information of university-industry-government relations: an indicator of the triple helix dynamics. Scientometrics, 58(2), 445-467. 
Leydesdorff, L. (2012). The triple helix, quadruple helix,..., and an N-tuple of helices: explanatory models for analyzing the knowledge-based economy? Journal of the Knowledge Economy, 3(1), 25-35.

Leydesdorff, L., \& Etzkowitz, H. (1996). Emergence of a triple helix of university-industry-government relations. Science and Public Policy, 23(5), 279-286.

Leydesdorff, L., \& Park, H. W. (2014). Can synergy in triple helix relations be quantified? A review of the development of the triple helix Indicator. Triple Helix, 1(1), 1-18.

Leydesdorff, L., \& Strand, Ø. (2013). The Swedish system of innovation: regional synergies in a knowledgebased economy. Journal of the American Society for Information Science and Technology, 64(9), 18901902.

Lindberg, M., Danilda, I., \& Torstensson, B. M. (2012). Women resource centres-a creative knowledge environment of quadruple helix. Journal of the Knowledge Economy, 3(1), 36-52.

Lindberg, M., Lindgren, M., \& Packendorff, J. (2014). Quadruple helix as a way to bridge the gender gap in entrepreneurship: the case of an innovation system project in the Baltic Sea region. Journal of the Knowledge Economy, 5(1), 94-113.

MacGregor, S. P., Marques-Gou, P., \& Simon-Villar, A. (2010). Gauging readiness for the quadruple helix: a study of 16 European organizations. Journal of the Knowledge Economy, 1(3), 173-190.

Manski, C. F. (2000). Economic analysis of social interactions. Journal of Economic Perspectives, 14(3), 115136.

McMullen, J. S., \& Dimov, D. (2013). Time and the entrepreneurial journey: the problems and promise of studying entrepreneurship as a process. Journal of Management Studies, 50(8), 1481-1512.

Moroz, P. W., \& Hindle, K. (2012). Entrepreneurship as a process: toward harmonizing multiple perspectives. Entrepreneurship Theory and Practice, 36(4), 781-818.

Nordberg, K. (2015). Enabling regional growth in peripheral non-university regions - the impact of a quadruple helix intermediate organisation. Journal of the Knowledge Economy, 6(2), 334-356.

Parente, R., Feola, R., Cucino, V., \& Catolino, G. (2015). Visibility and reputation of new entrepreneurial projects from academia: the role of start-up competitions. Journal of the Knowledge Economy, 6(3), 551567.

Perrini, F., Vurro, C., \& Costanzo, L. A. (2010). A process-based view of social entrepreneurship: from opportunity identification to scaling-up social change in the case of San Patrignano. Entrepreneurship and Regional Development, 22(6), 515-534.

Pettigrew, A. M. (1997). What is a processual analysis? Scandinavian Journal of Management, 13(4), 337348.

Prónay, S., \& Buzás, N. (2015). The evolution of marketing influence in the innovation process: toward a new science-to-business marketing model in quadruple helix. Journal of the Knowledge Economy, 6(3), 494 504.

Schoonmaker, M. G., \& Carayannis, E. G. (2013). Mode 3: a proposed classification scheme for the knowledge economy and society. Journal of the Knowledge Economy, 4(4), 556-577.

Steyaert, C. (1997). A qualitative methodology for process studies of entrepreneurship: creating local knowledge through stories. International Studies of Management \& Organization, 27(3), 13-33.

Steyaert, C. (2007). 'Entrepreneuring'as a conceptual attractor? A review of process theories in 20 years of entrepreneurship studies. Entrepreneurship and Regional Development, 19(6), 453-477.

Strannegård, L., \& Styhre, A. (Eds.). (2013). Management: an advanced introduction. Studentlitteratur AB, Lund, (p. 64).

Tsoukas, H., \& Chia, R. (2002). On organizational becoming: rethinking organizational change. Organization Science, 13(5), 567-582.

Verduyn, K. (2015). Entrepreneuring and process: a Lefebvrian perspective. International Small Business Journal, 33(6), 638-648.

Vetenskapsrådet, Good Research Practice (2011) Report number 1:2005 in the Swedish Research Council's report series, written by Bengt Gustafsson, Göran Hermerén and Bo Pettersson (pp. 65-71). Found at: www.vr.se. Accessed 25 Sept 2016. 